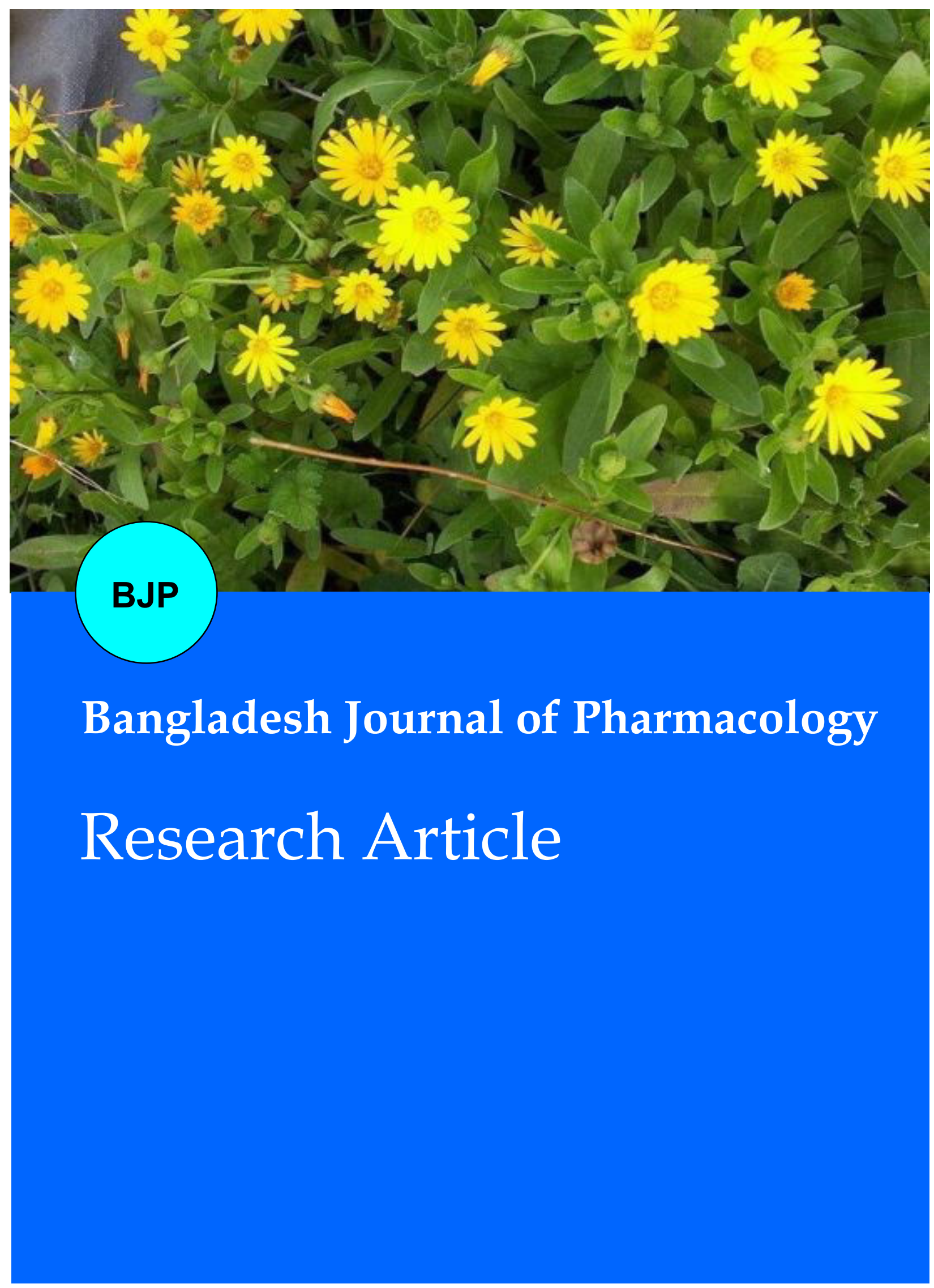




\title{
Anti-oxidant, antimicrobial and anti-acetylcholinesterase activities of organic extracts from aerial parts of three Tunisian plants and correlation with polyphenols and flavonoids contents
}

\author{
Imen Sellem, Fatma Kaaniche, Ahlem Chakchouk Mtibaa and Lotfi Mellouli
}

Laboratory of Microorganisms and Biomolecules of the Center of Biotechnolgy of Sfax-Tunisia. Road of Sidi Mansour, Km 6, B.P. 1177, 3018 Sfax-Tunisia.

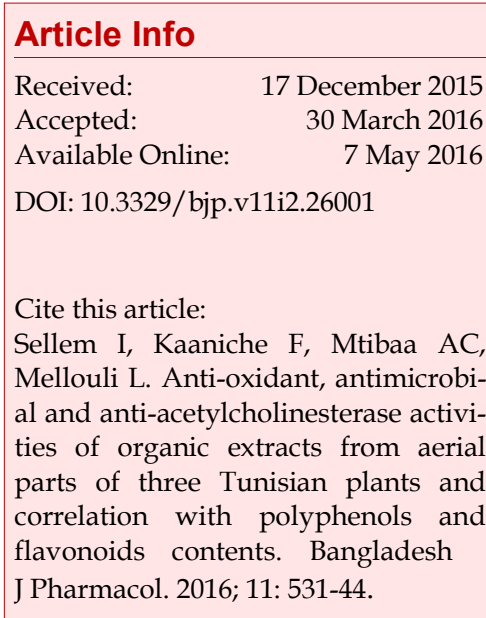

\begin{abstract}
In goal of searching new active compounds with important biological activities, a screening of several plants from salt-marsh region of Chebba-Tunisia had been realized. Three species had been selected: Calendula arvensis, Chenopodium murale and Nicotiana glauca. The organic extracts of different aerial parts of these plants (stems, leaves and flowers) displayed variable contents of total polyphenols (TPP) and total flavonoids (TF). Flowers acetone extract from $N$. glauca contained the higher quantity in TPP $(264.8 \pm 1.6 \mu \mathrm{g}$ $\mathrm{GA} / \mathrm{mg}$ ), while stems dichloromethane extract exhibited the best TF content $(49.8 \pm 2.2 \mu \mathrm{g} \mathrm{QE} / \mathrm{mg})$. The important TPP and TF contents reflected a good anti-oxidant and antimicrobial activities. The best acetylcholinesterase inhibitory activity had been shown in the fractions obtained after extraction with low polarity solvents. Whence, a correlation of flavonoids contents with biological activities had been shown, while, there was no correlation with acetylcholinesterase inhibitory activity.
\end{abstract}

\section{Introduction}

For centuries, extracts from plants have been used in traditional medicine to solve various health problems (Montiel Ruiza et al., 2013). Now-a-days, plants still play an important role in terms of prevention and cure of several diseases. They are the base for the development of modern medicine (Ameyaw and Duker-Eshun, 2009), and they have provided a great number of drugs (Kintzios and Barberaki, 2004).

The medicinal value of plants lies in the bioactive constituents, such as alkaloids, tannins, coumarins, terpenoids, phenolic compounds, etc (Chethan et al., 2012), that have been known to bear valuable therapeutic activities (Raina et al., 2014). Several studies showed significant variations of plants secondary metabolites production between spices and even for the same spices under different environmental conditions (Selmar and
Kleinwaëchter, 2013). Furthermore, in arid and semiarid regions, plants are often subjected to severe environmental conditions (salinity, drought, extreme temperatures etc), that influence secondary metabolites biosynthesis, especially the rise of phenolics production and distribution (Jallali et al., 2012).

The aims of this work were firstly, the gain of more information about total polyphenols and flavonoids quantities, the study of the potential natural antioxidant, antimicrobial and acetylcholinesterase inhibitory effect of diverse crude extracts from various areal parts of the three plants species from salt-marsh region of Chebba-Tunisia; Calendula arvensis, Chenopodium murale and Nicotiana glauca belonging respectively to Asteraceae, Chenopodiaceae and Solanaceae families, secondly to carry on the relationships between phenolics and flavonoids quantities and the different biological activities. 


\section{Materials and Methods}

\section{Chemicals and reagents}

The following chemicals and reagents were used: Cyclohexane (Riedel-deHaën), dichloromethane (Loba Chemie), ethyl acetate (Loba Chemie), acetone (Loba Chemie), acetonitrile (Loba Chemie), Folin-Ciocalteau reagent (Fluka), $\mathrm{Na}_{2} \mathrm{CO}_{3}$ (Merck), ascorbic acid (Bio Basic), butylated hydroxytoluene (BHT) (Supelco), gallic acid (Bio Basic), $\mathrm{AlCl}_{3}$ (Merck), quercetin (HWI Analitik), 2,2-diphenyl-1-picrylhydrazyl (DPPH) (Aldrich), DMSO (Scharlau), 2, 2'-azino-bis-(3-ethylbenz -thiazoline-6-sulfonic acid) (ABTS) (Fluka), $\mathrm{MK}_{2} \mathrm{~S}_{2} \mathrm{O}_{8}$ (Merck), $\beta$-carotene (Sigma), linoleic acid (Acros Organics), Tween 40 (Scharlau), peptone (Accumix), Yeast extract (Accumix), $\mathrm{NaCl}$ (Suvchem), agar (Biokar), glucose (Accumix), electric eel AChE (Type-VI -S, EC 3.1.1.7, Sigma), acetylthiocholine iodide (ATCI) (Sigma), 5,5'-dithiobis-(2-nitrobenzoic acid) (DTNB) (Sigma), Tris (Vivantis) and galanthamine (Sigma).

\section{Plants collection and extracts preparation}

C. arvensis, N. glauca and C. murale were collected from the marsh area of Chebba (Mahdia, Tunisia, latitude $35.23^{\circ}$ and longitude $11.11^{\circ}$ ), this region strong saline and had a semi-arid climate with scarce rainfall (Mabrouk et al., 2014; Saidi et al., 2009). The identification of the three plants species was performed according to the flora of Tunisia deposited in the Center of Biotechnology of Sfax.

The plants were washed and air-dried in the shade at room temperature. The areal parts were separated and grounded to fine powder using a grinder. Each material resulted was extracted by maceration in 5 solvents successively in increasing polarity (cyclohexanedichloromethane-ethyl acetate-acetone-acetonitrile) for 24 hours with a mass to volume ratio of $1: 10(\mathrm{~g} / \mathrm{mL})$, at room temperature. The resulting crude extracts were evaporated under rotary evaporator to dryness at $37^{\circ} \mathrm{C}$. The dried extracts were kept at $4^{\circ} \mathrm{C}$ in the dark until a further analysis.

\section{Total polyphenols content}

Total polyphenols content was determined according to Folin-Ciocalteau method (Waterman and Mole, 1994) with some modifications. $10 \mu \mathrm{L}$ of diluted extract solution was shaken for $5 \mathrm{~min}$ with $50 \mu \mathrm{L}$ of FolinCiocalteau reagent. Then $150 \mu \mathrm{L}$ of $20 \% \mathrm{Na}_{2} \mathrm{CO}_{3}$ was added and the mixture was shaken once again for 1 min. Finally, the solution was brought up to $790 \mu \mathrm{L}$ by adding distilled water. After 2 hours, the absorbance at $760 \mathrm{~nm}$ was evaluated using a spectrophotometer (Thermo Scientific / Genesys 20, Germany). Gallic acid was used as a standard for the calibration curve. Total polyphenolics content (TPP) of the extracts was calculated according to the following equations: $\mathrm{y}=$ $0.012 \mathrm{x}+0.017(\mathrm{r} 2=0.997)$, expressed as $\mu \mathrm{g}$ gallic acid equivalent per milligram of dry extract ( $\mu \mathrm{g} \mathrm{GA} / \mathrm{mg}$ ) using the linear equation based on the calibration curve.

\section{Flavonoids content}

The flavonoids content in extract was determined by spectrophotometric method (Quettier Deleu et al., 2000). Briefly, $1 \mathrm{~mL}$ of $\mathrm{AlCl}_{3}$ was added to $1 \mathrm{~mL}$ diluted extract solution and vortexed, and then incubated for 15 min in the dark. The absorbance at $430 \mathrm{~nm}$ was evaluated for the samples and the quercetin as standard for the calibration curve. Total flavonoids (TF) content of the extracts was calculated according to the following equations: $y=0.051 x+0,003(r 2=0.999)$, and expressed in $\mu \mathrm{g}$ of quercetin equivalent per milligram of dry plant extract $(\mu \mathrm{g} \mathrm{QE} / \mathrm{mg})$.

\section{Anti-oxidant assays}

All anti-oxidant activities were expressed as $\mathrm{EC}_{50}$ (the concentration that causes $50 \%$ of effect). The free radical scavenging activity of the three plants extracts had been assessed by 2.2-diphenyl-1-picrylhydrazyl (DPPH) and 2.2'- azino-bis (3-ethylbenzothiazoline-6-sulphonic acid) $\left(\mathrm{ABTS}^{+}\right)$radicals assays. Gallic acid (GA), ascorbic acid (AA) and butylated hydroxytoluene (BHT) were used as controls, they are well known anti-oxidant compounds.

\section{DPPH radical scavenging activity (Video clip)}

$\mathrm{DPPH}$ is one of the compounds that possess a proton free radical, when DPPH encounters proton radical scavengers its purple color fades rapidly. This assay determines the scavenging of stable radical species according to the method of Kirby and Schmidt, (1997) with slight modifications. Briefly, extracts were dissolved in $10 \%$ DMSO and diluted with ultrapure water at different concentrations $(500,250,125,60.25,30.125 \mu \mathrm{g} /$ $\mathrm{mL})$. Then, $500 \mu \mathrm{L}$ of a $4 \%(\mathrm{w} / \mathrm{v})$ solution of $\mathrm{DPPH}$ radical in methanol was mixed with $500 \mu \mathrm{L}$ of samples. The mixture was incubated for $30 \mathrm{~min}$ in the dark at room temperature. The scavenging capacity was determined spectrophotometrically by monitoring the decrease in absorbance at $517 \mathrm{~nm}$ against a blank. The percentage of antiradical activity (\%ArA) had been calculated as follows:

$\% \operatorname{ArA}=[($ absorbance of control - absorbance of test sample) / absorbance of control] x 100

\section{$\mathrm{ABTS}^{+}$radical scavenging activity}

The potential of extracts to scavenge free radicals was also assessed by their ability to quench $\mathrm{ABTS}^{+}$antiradical activity done by using the $\mathrm{ABTS}^{+}$free radical discoloration assay developed by Re et al. (1999) with some modifications. Briefly, the preformed radical monocation of $\mathrm{ABTS}^{+}$was generated by reacting 2.2' azino-bis-(3-ethylbenzthiazoline-6-sulfonic acid) (ABTS) solution $(7 \mathrm{mM})$ with $2.45 \mathrm{mM} \mathrm{K} \mathrm{S}_{2} \mathrm{O}_{8}$. The mixture was allowed to stand for 15 hours in the dark at room 
temperature. The solution was diluted with ethanol to obtain the absorbance of $0.7 \pm 0.2$ units at $734 \mathrm{~nm}$. Samples were separately dissolved in ethanol to yield the following concentrations $(500,250,125,60.25$, $30.125,15.625 \mu \mathrm{g} / \mathrm{mL})$. In order to measure the antioxidant activity of extracts and standards, $20 \mu \mathrm{L}$ of each sample at various concentrations was added to $180 \mu \mathrm{L}$ of $\mathrm{ABTS}^{+}$and vortexed for $30 \mathrm{sec}$, and then incubated for $6 \mathrm{~min}$ in dark at room temperature. The absorbance was measured spectrophotometrically at $734 \mathrm{~nm}$. The percentage of scavenging activity of $\mathrm{ABTS}^{+}(\% \mathrm{SA})$ was calculated by the following formula:

$\% \mathrm{SA}=[($ absorbance of control - absorbance of test sample) /absorbance of control] x 100

$\beta$-Carotene-linoleic acid bleaching assay

The extracts anti-oxidant activity was determined according to the $\beta$-carotene bleaching method described by Pratt (1980): $0.5 \mathrm{mg}$ of $\beta$-carotene was dissolved in 1 $\mathrm{mL}$ chloroform, and then $25 \mu \mathrm{L}$ of linoleic acid and 200 $\mu \mathrm{L}$ of Tween 40 were added. The chloroform was then evaporated under rotary evaporator, and the residue was dissolved in $100 \mathrm{~mL}$ of $\mathrm{H}_{2} \mathrm{O}$. Extracts were diluted at different concentrations $(500,250,125,60.25,30.125$ $\mu \mathrm{g} / \mathrm{mL}$ ), and for $500 \mu \mathrm{L}$ of each sample, $2.5 \mathrm{~mL}$ of $\beta$ carotene-linoleic acid solution was added. The absorbance was read at $470 \mathrm{~nm}$ firstly at zero time and after $120 \mathrm{~min}$ of incubation in dark at $50^{\circ} \mathrm{C}$. The antioxidant activity in $\beta$-carotene bleaching model in percentage $(\mathrm{AA} \%)$ was calculated using the following equation:

$\mathrm{AA} \%=\left[1-\left(\mathrm{A}^{0} \mathrm{~S}_{\mathrm{S}}-\mathrm{A}^{120} \mathrm{~S}\right) /\left(\mathrm{A}^{0} \mathrm{C}-\mathrm{A}^{120} \mathrm{C}\right)\right] \times 100$

where $\mathrm{A}^{0} \mathrm{~S}$ and $\mathrm{A}^{0} \mathrm{C}$ are absorbance of the sample and the control respectively measured at zero time, and $\mathrm{A}^{120_{S}}$ and $\mathrm{A}^{120} \mathrm{C}$ are absorbance of the sample and the control respectively measured after $120 \mathrm{~min}$

\section{Antimicrobial activities}

Microorganisms and growth conditions

Bacteria and Candida species were obtained from International Culture Collections (ATCC) and local culture collection of Laboratory of Microorganisms and Biomolecules of the Centre of Biotechnology of Sfax Tunisia. They included Gram-positive bacteria: Staphylococcus aureus ATCC 6538, Micrococcus luteus LB14110 and Listeria monocytogenes ATCC 19117 and Gram-negative bacteria: Salmonella typhimurium ATCC 14028, Pseudomonas aeruginosa ATCC 49189 and Enterobacter aerogenes ATCC 13048 and two Candida strains: Candida tropicalis R2 CIP 203 and C. albicans ATCC 10231.

The bacterial cultures were performed in Luria-Bertani (LB) agar medium composed of $(\mathrm{g} / \mathrm{L})$ : peptone 10; yeast extract 5; $\mathrm{NaCl} 5$ and agar 20 at $\mathrm{pH} 7.2$, then the bacterial strains were incubated at $37^{\circ} \mathrm{C}$, except $M$. luteus and $P$. aeruginosa which are incubated at $30^{\circ} \mathrm{C}$. The Candida species were cultured on Sabouraud agar medium composed of (g/L): peptone 10; glucose 10 and agar 20 at $\mathrm{pH}=5.6$ and incubated at $28^{\circ} \mathrm{C}$. Working bacterial cultures were prepared by inoculating a loopful of each test bacteria in $3 \mathrm{~mL}$ of LB broth. $C$. tropicalis was cultured in YP10 medium composed of (g/L): yeast extract 10; peptone 10; glucose 100 and 15 $\mathrm{mL}$ of $2 \mathrm{~g} / \mathrm{L}$ adenine solution, while C. albicans was cultured in YEPD medium composed of $(\mathrm{g} / \mathrm{L})$ : yeast extract 10; peptone 20 and dextrose 20 at $\mathrm{pH}$ 5.6. All strains were incubated at adequate temperature for 12 hours. For the test, final inoculum concentrations of $10^{6}$ $\mathrm{CFU} / \mathrm{mL}$ were used.

\section{Agar diffusion method}

In this research, the antimicrobial activities of each crude extract were assessed by diameters of inhibition areas (halo) in $\mathrm{mm}$, by means of agar-well diffusion assay according to Güven et al. (2006) with some modifications. Fifteen milliliters of the molten agar $\left(45^{\circ}\right.$ C) were poured into sterile petri dishes ( $\varnothing 90 \mathrm{~mm})$. Working cell suspensions were prepared and $100 \mu \mathrm{L}$ was evenly spreaded onto the surface of the agar plates of LB agar medium for bacteria and sabouraud agar medium for Candida. Once the plates had been aseptically dried, $5 \mathrm{~mm}$ wells were punched into the agar with a sterile pasteur pipette. The extracts were dissolved in dimethylsulfoxide (DMSO)/water (1/9; v/ $\mathrm{v})$ to a final concentration of $100 \mathrm{mg} / \mathrm{mL}$ and then filtered through $0.22 \mu \mathrm{m}$ pore-size black polycarbonate filters (Millipore). Thus, $100 \mu \mathrm{L}$ were placed into the wells and the plates were incubated at adequate temperature overnight for bacterial strains and 72 hours for Candida strains.

\section{Acetylcholinesterase inhibitory potential}

AChE inhibitory activity was measured by slightly modified spectrophotometric method of Ellman et al. (1961). Electric eel AChE was used, while acetylthiocholine iodide (ATCI) was employed as substrate of the reaction. 5.5'-dithiobis-(2-nitrobenzoic acid) (DTNB) was used for the measurement of the antiacetylcholinesterase activity. Briefly, in this method, 100 $\mu \mathrm{L}$ of Tris buffer at $50 \mathrm{mM}$ ( $\mathrm{pH} 8.0), 30 \mu \mathrm{L}$ of sample or standard and $5 \mu \mathrm{L}$ of AChE enzyme $(0.5 \mathrm{U} / \mathrm{mL})$ were added in a 96 well microplate and incubated for $10 \mathrm{~min}$ at $25^{\circ} \mathrm{C}$. Then, $142 \mu \mathrm{L}$ of DTNB $(3 \mathrm{mM})$ and $23 \mu \mathrm{L}$ of substrate $(75 \mathrm{mM})$ were added. Hydrolysis of ATCI was monitored by the formation of the yellow 5-thio-2nitrobenzoate anion as a result of the reaction of DTNB with thiocholines, catalyzed by enzymes at $405 \mathrm{~nm}$ utilizing a 96-well microplates reader (Thermo Scientific/Varioskan Flash, Germany). The kinetic reaction has been followed until the AChE activity decreased, and then the reaction has been stopped. Percentage of inhibition of AChE was determined by 
comparison of rates reaction of samples relative to control (10\% DMSO in Tris buffer) using the following formula:

$\%$ AChEI $=1-\left(\delta A_{\text {sample }} / \delta A_{\text {control }}\right) \times 100$

Where $\delta A$ sample: Sample absorbance at zero time Sample absorbance at the end of reaction, and $\delta A_{\text {control: }}$ Control absorbance at zero time - Control absorbance at the end of reaction.

Galanthamine, the antiacetylcholinesterase alkaloidtype of drug obtained from the bulbs of snowdrop (Galanthus sp.), was used as standard.

Firstly, all extracts have been tested at $100 \mu \mathrm{g} / \mathrm{mL}$ of concentration. Then, dose-dependent AChE inhibitory activity (of extracts that display an activity with $100 \mu \mathrm{g} /$ $\mathrm{mL}$ of concentration) was further studied and the results are shown in the IC50 values.

\section{Statistical analyses}

All tests are assayed in triplicate and expressed as the average \pm standard deviation of the measurements. The statistical program SPSS version 21.00 for Windows (SPSS Inc., Chicago, IL) was used to analyse data. Variance was analysed by one-way ANOVA and Duncan's multiple range tests were calculated for the significant data at $p<0.05$. Correlation between the phenolic and the flavonoids contents and biological activities in plant extracts were analysed by Pearson correlation coefficient.

\section{Results}

\section{Total polyphenols and flavonoids contents}

TPP contents of the extracts from aerial parts of the three plants were tabulated in Table I. Overall, the values appear to vary between $16.2 \pm 0.4$ and $264.8 \pm 1.1$ $\mu \mathrm{g}$ GA/mg. Concerning TPP contents in C. arvensis extracts, the values are ranged from $26.8 \pm 0.2 \mu \mathrm{g} \mathrm{GA} /$ $\mathrm{mg}$ (Flowers cyclohexane extract) to $188.3 \pm 0.2 \mu \mathrm{g} \mathrm{GA} /$ $\mathrm{mg}$ (leaves dichloromethane extract). For C. murale, polyphenols lowest concentration has been shown with stems acetonitrile extract $(16.2 \pm 0.4 \mu \mathrm{g} \mathrm{GA} / \mathrm{mg})$, while flowers acetonitrile extract showed the highest concentration $(215.3 \pm 0.3 \mu \mathrm{g} \mathrm{GA} / \mathrm{mg}) . N$. glauca extracts presented a polyphenols contents ranged from $20.8 \pm$ $0.2 \mu \mathrm{g} \mathrm{GA} / \mathrm{mg}$ for the stems cyclohexane extract to $264.8 \pm 1.1 \mu \mathrm{g}$ GA/mg for the flowers acetonitrile extract.

TF contents of the extracts are shown in Table I. Globally, the values varied between zero to $49.8 \pm 0.0$ $\mu \mathrm{g} \mathrm{QE} / \mathrm{mg}$. For $C$. arvensis values were ranged from 0 $\mu \mathrm{g} \mathrm{QE} / \mathrm{mg}$ (stems cyclohexane extract), to $43.0 \pm 0.0 \mu \mathrm{g}$ $\mathrm{QE} / \mathrm{mg}$ (flowers acetonitrile extract). Concerning $C$. murale the lowest flavonoids content had been obtained in the flowers cyclohexane extract $(0.4 \pm 0.0 \mu \mathrm{g} Q \mathrm{QE} / \mathrm{mg})$ and the highest content had been shown in the leaves dichloromethane extract $(49.2 \pm 0.1 \mu \mathrm{g} \mathrm{QE} / \mathrm{mg})$. While, $N$. glauca had the lowest content of flavonoids in the stems dichloromethane extract $(5.4 \pm 0.3 \mu \mathrm{g} \mathrm{QE} / \mathrm{mg})$ and the highest one in the flowers dichloromethane extract $(49.8 \pm 0.0 \mu \mathrm{g} \mathrm{QE} / \mathrm{mg})$.

\section{Anti-oxidant power}

The results of anti-oxidant activities are shown in Table II. As regard DPPH radical scavenging activity, EC50 values of the extracts are ranged from $41.4 \pm 1.6 \mu \mathrm{g} / \mathrm{mL}$ (Flowers acetonitrile extract from $N$. glauca) to $>500 \mu \mathrm{g} /$ $\mathrm{mL}$ for several extracts. The EC50 values of GA, AA and BHT content were found to be $3.6 \pm 0.0,4.2 \pm 0.1$ and $28.6 \pm 0.3 \mu \mathrm{g} / \mathrm{mL}$ respectively. Discoloration of $\mathrm{ABTS}^{+}$ reflects the capacity of anti-oxidant species to donate electrons or hydrogen atoms to inactivate this radical cation. In this finding, the $\mathrm{EC}_{50}$ of the different extracts in $\mathrm{ABTS}^{+}$assay are widely variable, they are ranged between $10.8 \pm 0.2 \mu \mathrm{g} / \mathrm{mL}$ (Stems dichloromethane extract from C. arvensis) to $100.5 \pm 0.6 \mu \mathrm{g} / \mathrm{mL}$ (Stems cyclohexane extract from C. murale).

There was a correlation between degradation rate and the bleaching of b-carotene; where, the extract with the lowest $\beta$-carotene degradation rate exhibits the highest anti-oxidant activity. In this work, extracts showed a large variation of their protective action against bleaching of $\beta$-carotene, the $\mathrm{EC}_{50}$ values are ranged from $38 \mu \mathrm{g} / \mathrm{mL}$ (Ethyl acetate extract from C. murale leaves) to $>500 \mu \mathrm{g} / \mathrm{mL}$ for several extracts. The $\mathrm{EC}_{50}$ value of BHT is $72.7 \pm 0.3 \mu \mathrm{g} / \mathrm{mL}$. Several extracts from these 3 plants exhibited better activities than BHT.

In this work, extracts showed a large variation of their protective action against bleaching of $\beta$-carotene, the $\mathrm{EC}_{50}$ values are ranged from $38 \mu \mathrm{g} / \mathrm{mL}$ (Ethyl acetate extract from C. murale leaves) to $>500 \mu \mathrm{g} / \mathrm{mL}$ for several extracts. The $\mathrm{EC}_{50}$ value of BHT is $72.7 \pm 0.3 \mu \mathrm{g} / \mathrm{mL}$. Several extracts from these 3 plants exhibit better activities than BHT.

These results revealed that considerable antiradical components were contained in the different plants parts. Differences in species and in solvents polarities and thus different extractability of the anti-oxidant components may explain the differences in anti-oxidant activity of the extracts from the three plants.

\section{Antimicrobial activities}

The results against both bacterial and Candida species are presented in Figure 1-3. For C. arvensis, leaves extracts showed the best activities (Figure 1B), especially in acetonitrile extract, which gave inhibition diameters of $20.4 \pm 0.6,15.0 \pm 0.0$ and $15.6 \pm 0.2 \mathrm{~mm}$ respectively against Candida tropicalis, Pseudomonas aeruginosa and Enterobacter aerogenes. While, the leaves 


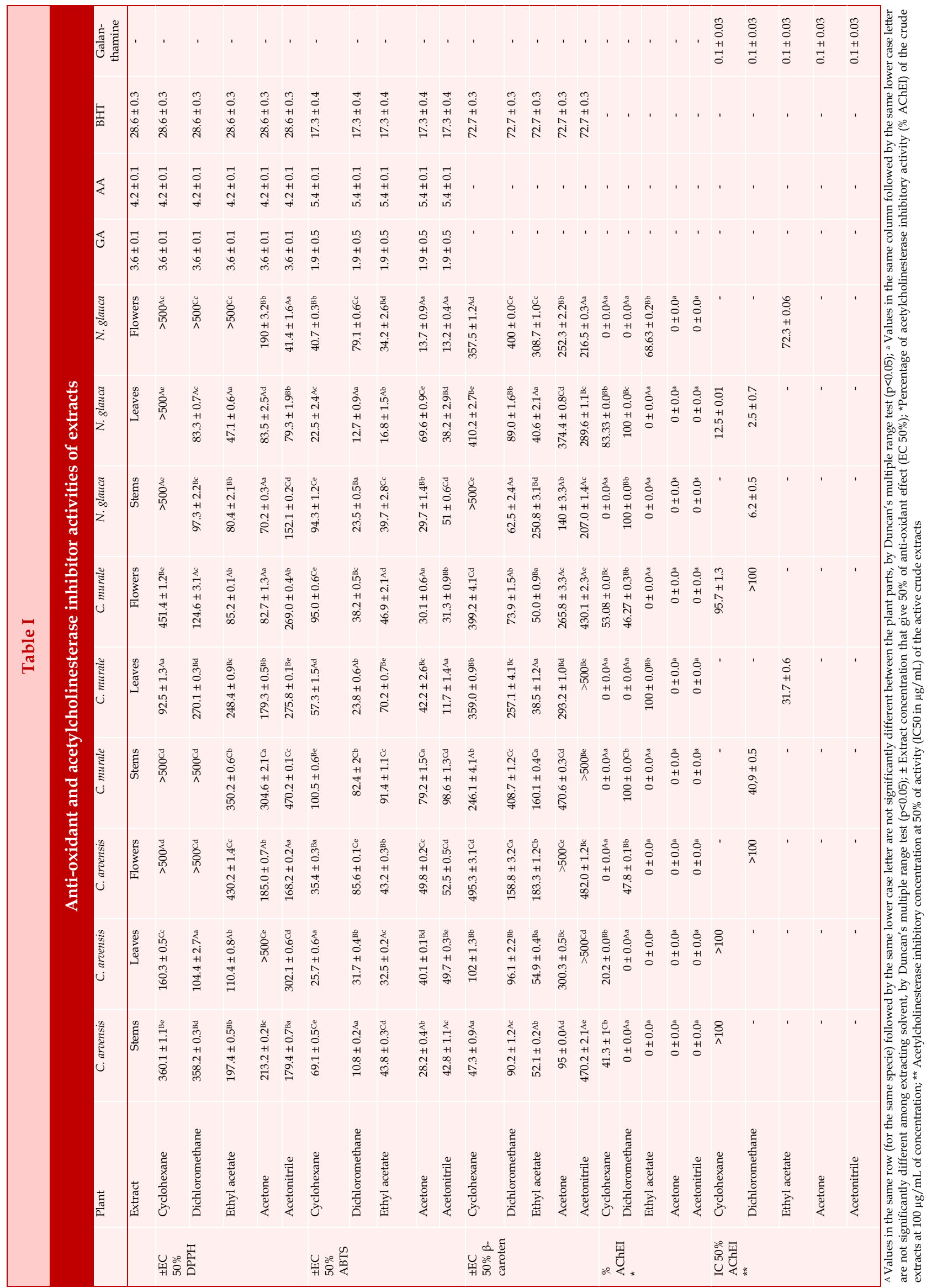




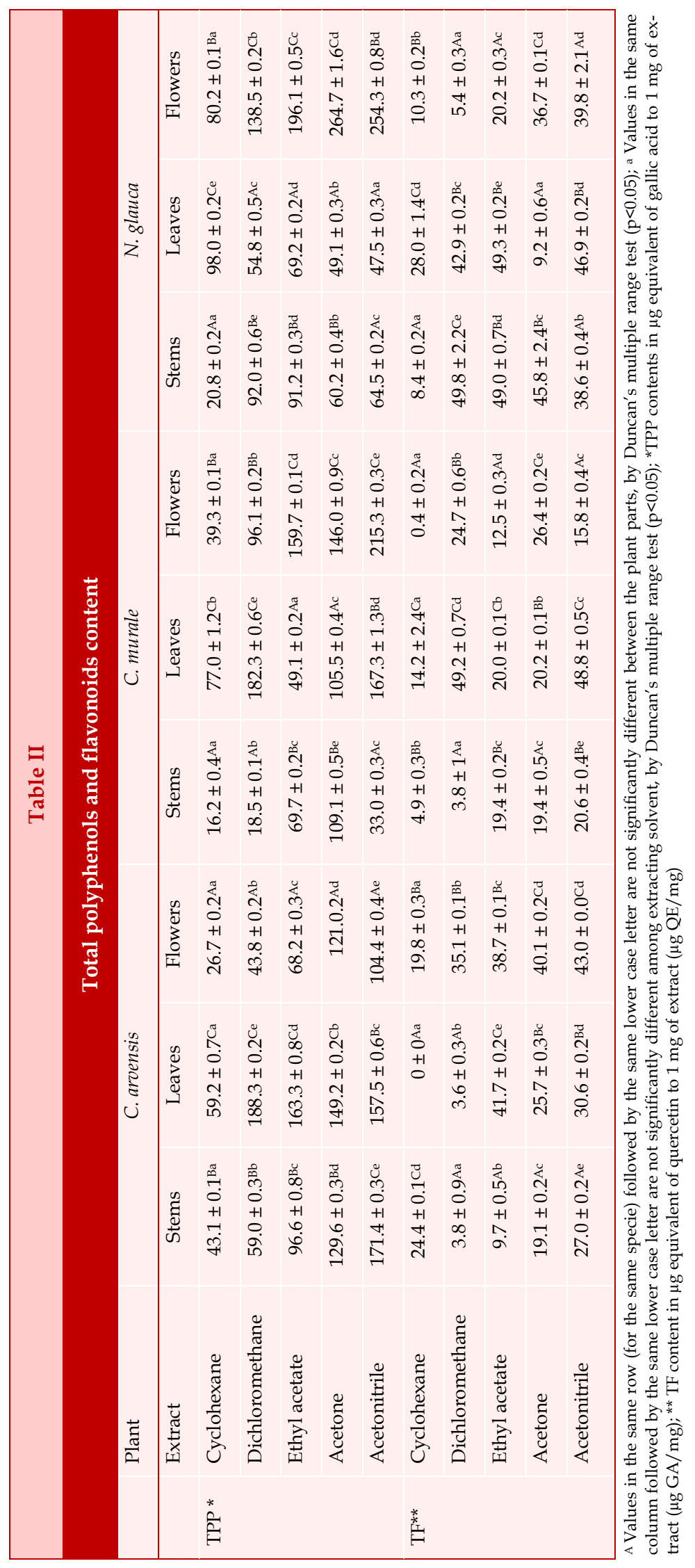


acetone and ethyl acetate extracts were the most active respectively against Salmonella typhimarium $(27.1 \pm 0.2$ $\mathrm{mm}$ ) and Candida albicans (20.0 $\pm 0.1 \mathrm{~mm})$. Flowers extracts carried out good activities against some pathogens species (Figure 1C), indeed, ethyl acetate extract exhibited the best activity against $L$. monocytogenes $(40.7 \pm 1.1 \mathrm{~mm})$, and acetone extract was the most active against $M$. luteus $(34.9 \pm 0.2 \mathrm{~mm})$, while the best activity against $S$. aureus has been shown in acetonitrile extract $(20.0 \pm 0.0 \mathrm{~mm})$. C. murale extracts seemed to be less active than the two others species extracts. Indeed, the best activities were shown for flowers acetonitrile extract (Figure 2C), especially for $C$. albicans $(19.1 \pm 0.1 \mathrm{~mm}), P$. aeruginosa $(30.2 \pm 0.1 \mathrm{~mm}), S$. typhimarium $(25.0 \pm 0.0 \mathrm{~mm})$, L. monocytogenes $(34.7 \pm 0.6$ $\mathrm{mm})$, M. luteus $(30.9 \pm 1.1 \mathrm{~mm})$ and $S$. aureus $(22.1 \pm 1.8$ $\mathrm{mm}$ ). While leaves acetonitrile extract (Figure 2B) exhibited the best activities against $C$. tropicalis $(5.1 \pm 0.3$ $\mathrm{mm})$ and E. aerogenes $(33.93 \pm 0.09 \mathrm{~mm})$. N. glauca leaves crude extracts (Figure 3B) were the most active: Ethyl acetate extract presents the best activities against $S$. typhimurium $(29.7 \pm 1.3 \mathrm{~mm})$, E. aerogenes $(47.2 \pm 0.7$ $\mathrm{mm})$, L. monocytogenes $(50.1 \pm 0.2 \mathrm{~mm})$, M. luteus $(54.0 \pm$ $0.0 \mathrm{~mm})$ and $S$. aureus $(26.2 \pm 1.0 \mathrm{~mm})$. While, acetonitrile and ethyl acetate extracts had fairy the same activities against $C$. tropicalis $(10.0 \pm 0.0$ and $10.1 \pm 0.1$ $\mathrm{mm}$, respectively). Dichloromethane extract had the best activities against $C$. albicans $(12.1 \pm 0.5 \mathrm{~mm})$ and $P$. aeruginosa $(31.0 \pm 0.2 \mathrm{~mm})$.

Globally, by comparing the three species aerial parts extracts, N. glauca leaves ethyl acetate extract was the most active against the three Gram+ bacteria strains and against E. aerogenes, while, $N$. glauca leaves was the best against $P$. aeruginosa. Moreover, $C$. arvensis leaves ethyl acetate, acetone, and acetonitrile extracts were the most active respectively against $C$. albicans, $S$. typhimarium and $C$. tropicalis. In comparison with findings in other studies, we remark that several extracts from the three plants exhibit a good activity against the used microbial strains.

\section{Acetylcholinesterase inhibition}

The results of AChEI are tabulated in Table II. Extracts from $C$. arvensis displayed the weakest inhibitory activities, even the most active one (flowers dichloromethane extract) had an $\mathrm{IC}_{50}$ above $100 \mu \mathrm{g} / \mathrm{mL}$. Extracts from $C$. murale exhibited moderate activity. The most potent one was the leaves ethyl acetate extract (31.7 \pm $0.6 \mu \mathrm{g} / \mathrm{mL}$ ). While, extract from $N$. glauca seemed to be most powerful AChE inhibitors, especially leaves dichloromethane extract which displayed the highest activity (IC50\% $=2.5 \pm 0.8 \mu \mathrm{g} / \mathrm{mL}$ ). The \% AChEI is remarkably influenced by the solvent type, indeed dichloromethane extract exhibited the best activities, followed by cyclohexane extracts then ethyl acetate extracts, while none of acetone or acetonitrile extracts has shown activity with a concentration less than 100 $\mu \mathrm{g} / \mathrm{mL}$. Thus, the best AChEI activity appears in extracts obtained by maceration in solvents with weak polarity.

\section{Correlation}

In this study, there was not a correlation between TPP content and TF content ( $22=0.225)$, and for the antioxidant assays, only ABTS ${ }^{+}$activity had correlation with $\mathrm{TPP}$ content $(\mathrm{R} 2=-0.525)$. Concerning antimicrobial activities, there was a weak correlation between TPP content and the activities against C. albicans, $S$. typhimarium, E. aerogenes and S. aureus (R2 were 0.337, $0.334,0.322$ and 0.320 , respectively) $p<0.1$, the correlation was more important with M. luteus (R2 = $0.410) \mathrm{p}<0.01$. Whereas, a distinct correlation between the amounts of TF content with the anti-oxidant and antimicrobial activities was revealed. Although a trend can be found, relating the higher content of TF to the $\mathrm{DPPH}$ activity $(\mathrm{R} 2=-0.421)$ and $\mathrm{ABTS}^{+}$activity $(\mathrm{R} 2=-$ $0.460) \mathrm{p}<0.01$, therefore, this good correlation suggests that flavonoids compounds, present in the extracts from the three plants play an important role as anti-radicals. While, TF and $\beta$-carotene test were not correlated $(\mathrm{R} 2=$ -0.058). Furthermore, TF content and the antimicrobial activities were highly correlated $(\mathrm{p}<0.01)$ with all the pathogenic strains. As regards the AChEI activity, no correlation was noticed with any of the other parameters.

\section{Discussion}

Our results show that TPP and TF contents varied depending on solvent used for the extraction and plant part. Acetonitrile extracts seemed to be the richest in $\mathrm{TF}$, and leaves extracts seemed to contain the major quantities of TPP and TF, except for N. glauca that exhibited the highest content in TPP in flowers extracts. Concerning the antiradical capacity assayed by the most commonly used test based on DPPH and ABTS ${ }^{+}$ radicals scavenging (Liu et al., 2014), results reveal flatulence antiradical potential, which statistically dependent on flavonoids content, while the results of $\beta$ carotene-linoleic acid bleaching system had correlation neither with TPP content nor with TF content.

Then, the assessment of extracts antimicrobial activity had been performed and their positive relationship with TTP and TF contents had been likewise highlighted by studying their correlation.

In this study we have also assessed the acetylcholinesterase inhibitory power; results reveal that the active extracts were those obtained by extraction with low polarity solvents, and the higher activity had been shown with the cyclohexanic extract from N. glauca flowers. 


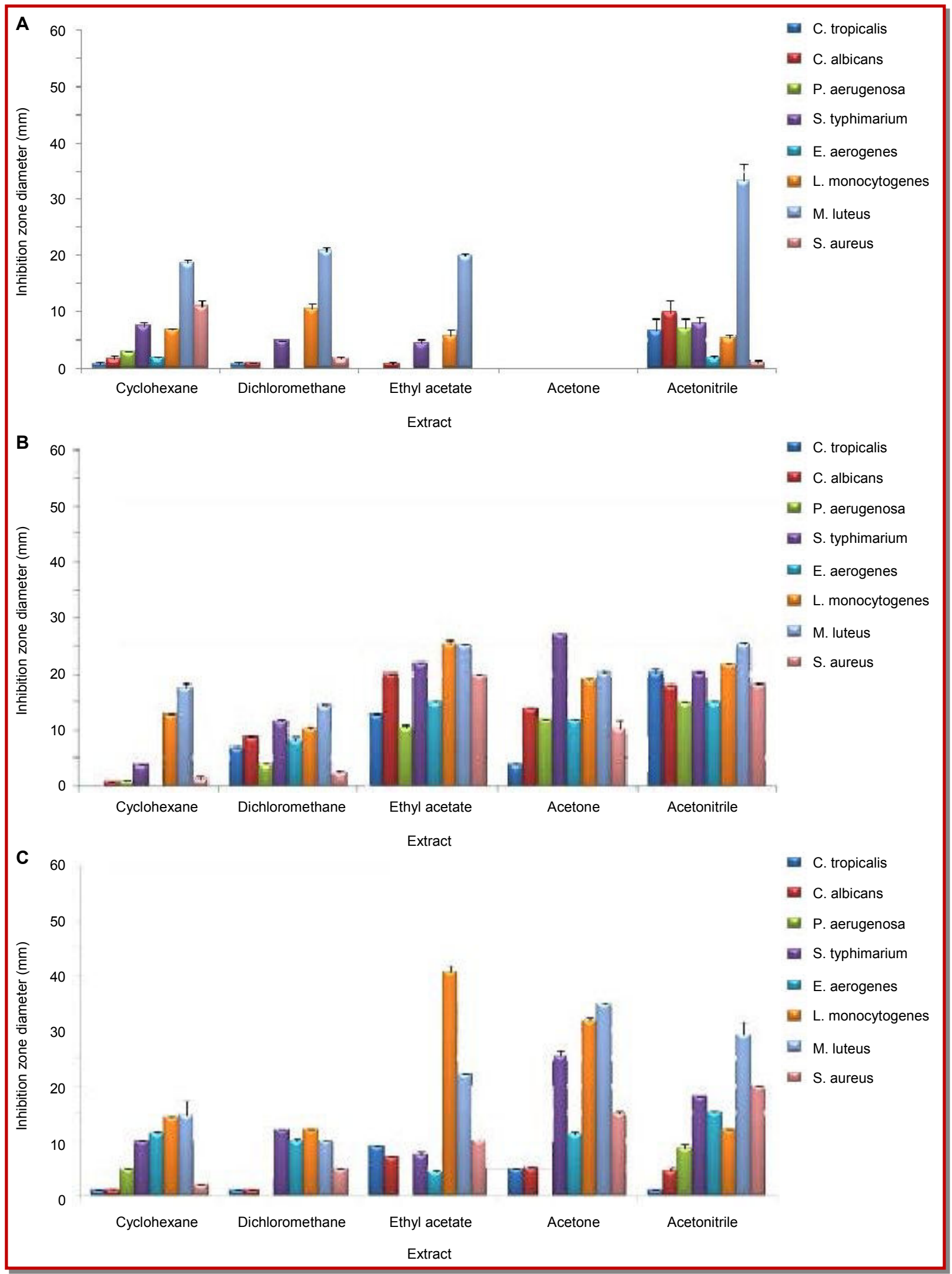

Figure 1: C. arvensis extracts antimicrobial activities by agar diffusion test (inhibition zone in $\mathrm{mm}$ ). (A) stems extracts activities, (B) leaves extracts activities, $(\mathrm{C})$ flowers extracts activities 


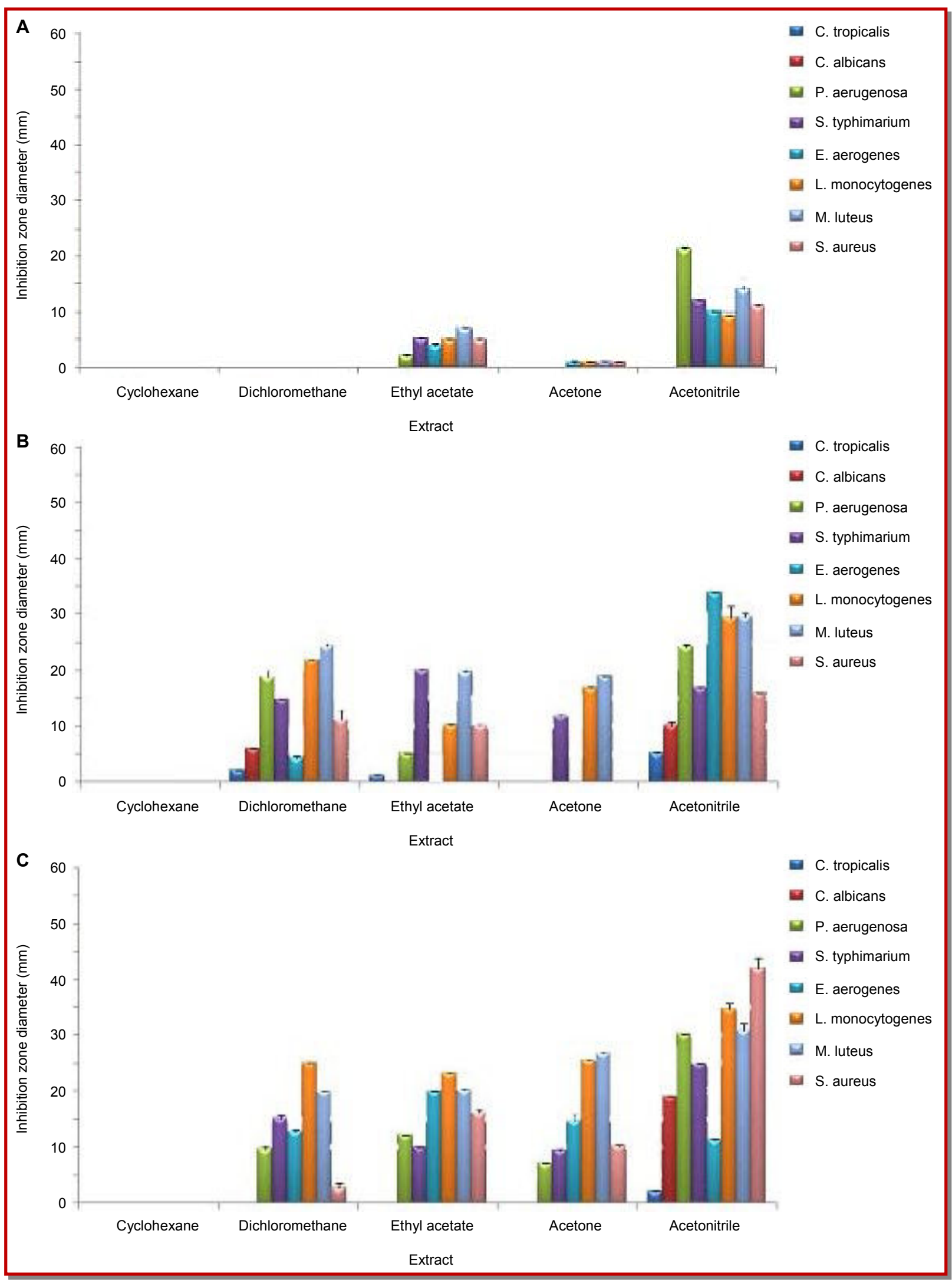

Figure 2: C. murale extracts antimicrobial activities by agar diffusion test (inhibition zone in mm). (A) stems extracts activities, (B) leaves extracts activities, $(C)$ flowers extracts activities 


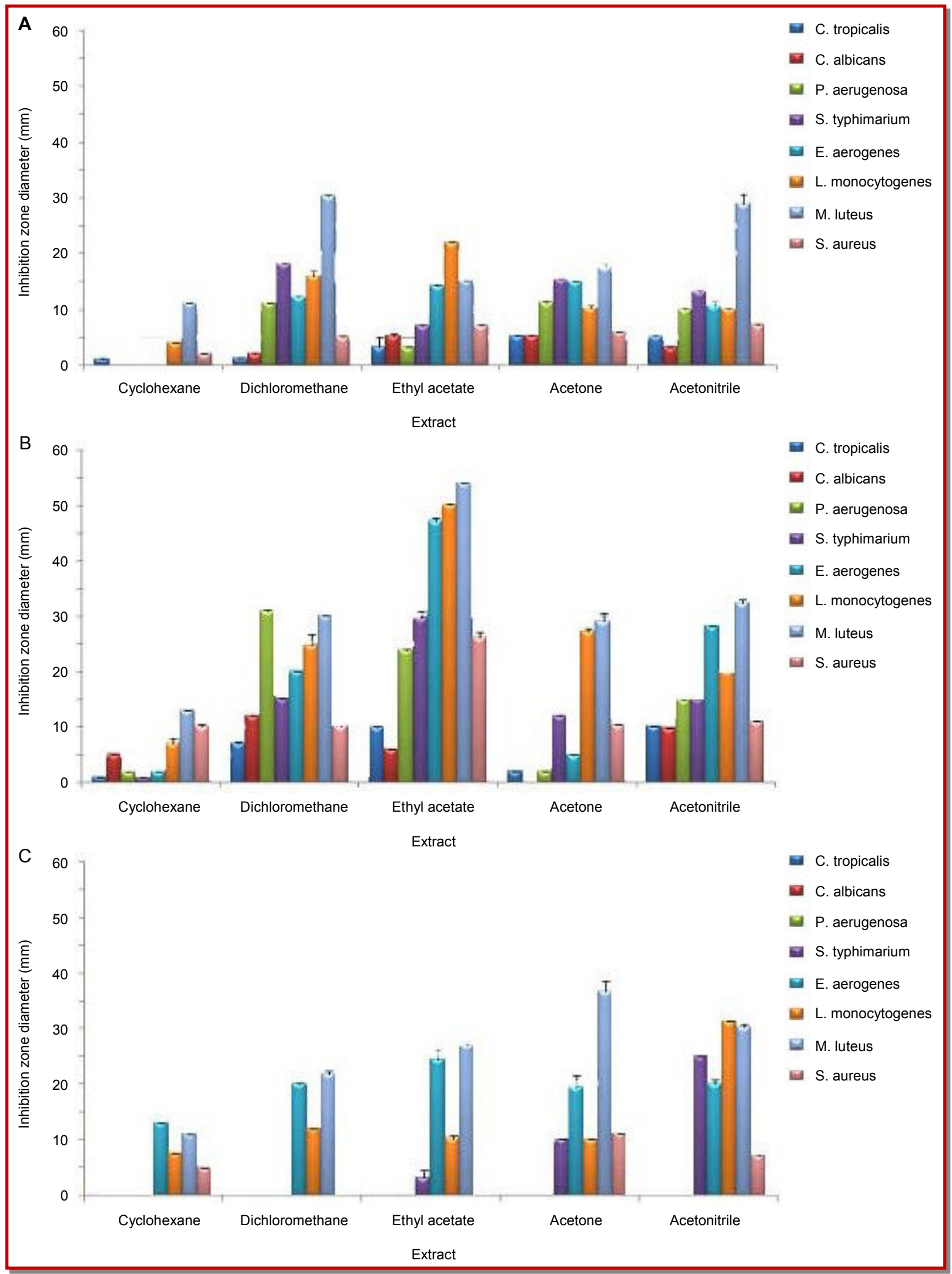

Figure 3: N. glauca extracts antimicrobial activities by agar diffusion test (inhibition zone in mm). (A) stems extracts activities, (B) leaves extracts activities, (C) flowers extracts activities 
In comparison with other studies for the same species, much more important quantities of TPP and TF have been remarked in our findings. Indeed, Ercetin et al. (2012) found a TPP content of $43 \mu \mathrm{g}$ GA/mg approximately in flowers dichloromethane extract from C. arvensis, which is similar to our result $(43.8 \pm 0.1 \mu \mathrm{g}$ $\mathrm{GA} / \mathrm{mg}$ ), however, for the same extract, they found a weak quantity of TF (5 $\mu \mathrm{g} \mathrm{QE} / \mathrm{mg}$ ) while we found 35.1 $\pm 0.1 \mu \mathrm{g} \mathrm{QE} / \mathrm{mg}$. Other study showed that a methanolic extract of flowers from $C$. arvensis exhibited a TPP and TF contents of $14.5 \pm 0.4 \mu \mathrm{g}$ GA/mg and $5.3 \pm 0.4 \mu \mathrm{g}$ $\mathrm{QE} / \mathrm{mg}$, respectively (Cetkovic et al., 2004), and this quantities are much fewer than the contents found with all flowers extracts in our work. For N. glauca, Tabana et al. (2015) reported that an organic fraction from this plant contain 108.2 $\mu \mathrm{g} \mathrm{GA} / \mathrm{mg}$ of TPP and $20.8 \mu \mathrm{g} \mathrm{QE} /$ $\mathrm{mg}$ of $\mathrm{TF}$, in our work we found a much higher quantities, for example, the TPP content in flowers acetone extract was $264.8 \pm 1.6 \mu \mathrm{g} \mathrm{GA} / \mathrm{mg}$ and the TF for the same extract was $36.7 \pm 0.1 \mu \mathrm{g} Q \mathrm{QE} / \mathrm{mg}$. grown.

Concerning anti-oxidant activities, our findings seem to be better than results reported from other works on these three plants, indeed, Ercetin et al. (2012) findings showed that extracts from $C$. arvensis exhibits a weak DPPH anti-radical activity $\left(\mathrm{EC}_{50} \%>1000 \mu \mathrm{g} / \mathrm{mL}\right.$ for all extracts), while in our work we found that extracts from this same plant present a potent activity. Furthermore, Tabana et al. (2015) indicated that an extract from $N$. glauca had been exhibit an anti-radical activities against $\mathrm{DPPH}$ and ABTS of $86.7 \mu \mathrm{g} / \mathrm{mL}$ and $67.6 \mu \mathrm{g} / \mathrm{mL}$ respectively, besides, we found a much better activities with several extracts from this same plant. For antimicrobial activities, it had been demonstrated that C. arvensis methanol and hexane extracts from flowers are able to inhibit some pathogen such as S. aureus, $L$. monocytogenes and $P$. aeruginosa, while the aqueous extract is unable to inhibit them (Abudunia et al., 2014), moreover the inhibitory capacity of these extracts against $S$. aureus and L. monocytogenes remain weaker than our results found with $C$. arvensis flowers extracts. Indeed in our work the largest zones of inhibition of the pathogens were respectively $20.0 \pm 0.1 \mathrm{~mm}$ (Acetonitrile extract), $40.7 \pm 1.1 \mathrm{~mm}$ (Ethyl acetate extract), while the best result against $P$. aeruginosa in our work was found in acetonitrile extract (Zone of inhibition reached $8.7 \pm$ $0.6 \mathrm{~mm}$ of diameter) and it is less active than $C$. arvensis flowers methanolic extract (Abudunia et al., 2014). No data about antimicrobial activity from other areal parts of this plant. Concerning C. murale antimicrobial potential, Zain et al. (2012) found that methanolic extract of $C$. murale leaves is active against $P$. aeruginosa and $C$. albicans, but unable to inhibit $S$. typhimurium, $M$. luteus and S. aureus. Awadh Ali et al. (2001) found the lack of activity of the whole plant methanolic extract against $S$. aureus and also $P$. aeruginosa. In other study (Ahmad et al., 2003), they found that the whole crude methanolic extract is inactive against C. albicans, $S$. aureus and $S$. typhimurium, but exhibited a medium activity against $P$. aeruginosa (Zone of inhibition reached $16 \mathrm{~mm})$. Nevertheless in our work, C. murale extracts had a good inhibitory activity against these pathogens, for example, leaves acetonitrile extract gave important activity with zones of inhibition that reached $10.2 \pm 0.6$ $\mathrm{mm}, 24.3 \pm 0.4 \mathrm{~mm}, 17.0 \pm 0.2 \mathrm{~mm}, 29.7 \pm 0.6 \mathrm{~mm}$ and $15.9 \pm 0.2 \mathrm{~mm}$ respectively against $C$. albicans, $P$. aeruginosa, S. typhimurium, M. luteus and S. aureus. As regards $N$. glauca, studies reported its cytotoxic activities against pathogens, indeed, Abdel Rahman et al. (2011) found that hexane and methanol extracts from $N$. glauca whole aerial part inhibit weakly different strains of S. aureus but don't inhibit L. monocytogenes, while in our case all extracts from each areal part (Stems, leaves and flowers) had strongly inhibiting both $S$. aureus and L. monocytogenes.

Concerning AChEI activity, although the potent activities of organic extracts from C. arvensis flowers and leaves reported by Ercetin et al. (2012), they remain weak comparing with our findings. Literature didn't reported AChEI activity for C. murale and N. glauca.

Phenolics are very important plant constituents; they exhibit anti-oxidant activity by inactivating free radicals or preventing decomposition of hydroperoxides into free radicals. The intermediate compounds formed by the action of the phenolic anti-oxidants are relatively stable due to charge distribution throughout the aromatic ring system (Costamagna et al., 2013; Maisuthisakul et al., 2007). This large variation of TPP and TF contents in the different extracts from the three plants can be explained by the varying solubility of the phenolic compounds in the used solvents, and this due to the difference of solvent polarities (Marinova and Yanishlieva, 1997). Furthermore, the different parts of plants are known to contain varying quantities of bioactive compounds, indeed, most phenolic compounds and flavonoids were found in the leaf extract, due to photosynthesis in this organ (Andersen and Markham, 2006).

The high correlation between flavonoids content and anti-radical capacity is due to hydroxyl groups in flavonoids molecules that confer scavenging ability on them (Emeka et al., 2015). As regard $\beta$-carotene bleaching system, linoleic acid produces hydroperoxides as free radicals during incubation at $50^{\circ}$ C. Beta-carotene undergoes rapid discoloration in the absence of anti-oxidants, while, the presence of antioxidants in the extracts will minimize its oxidation by the hydroperoxides (Kchaou et al., 2016). This hydroperoxides formed in this system will be neutralized by anti-oxidants. Thus, the degradation rate of $\beta$-carotene depends on the anti-oxidant capacity. In the present work, several extracts from the three plants 
had shown an excellent capacity to protect $\beta$-carotene from discoloration, thus, there are able to neutralize hydroperoxides. It is important to develop new compounds that protect $\beta$-carotene from degradation because of the strong biological activity and physiological important role of this pigment (Maisarah et al., 2014).

The antimicrobial ability of the extracts in this work can be attributed to levels of phenolics contents, especially flavonoids levels, which was making out by numerous studies (Özçelik et al., 2011). Indeed, the effectiveness of flavonoids against several pathogenic bacteria and fungi had been carried out (Rauha et al., 2000; Sohn et al., 2004), and researches had make evidence that flavonoids are able to form complexes with extracellular soluble proteins which bind to the bacterial cell wall (Tsuchiya et al., 1996).

Inhibition of acetylcholinesterase (AChE), the key enzyme in the breakdown of acetylcholine, is considered as a promising strategy for the treatment of neurological disorders such as Alzheimer's disease, senile dementia, ataxia and myasthenia gravis (Mukherjeea et al., 2007). In our findings, extracts obtained by low polarity solvents like cyclohexane and dichloromethane exhibited the strongest AChEI activity which hadn't any correlation with TPP and TF contents. This may due to power of other compounds presents in the three plants such as alkaloids, a nonpolar compounds. Indeed, many studies make out the effectiveness of alkaloids like a strong AChE inhibitors (Ahmed et al., 2013; Murraya et al., 2013). Moreover, many Alzheimer's drugs are made from plants alkaloids or their derivatives ( $\mathrm{Ng}$ et al., 2015; Dall' Acqua, 2013).

The great activity from N. glauca (in leaves dichloromethane extract) can be explained by the fact that this plant contains some compounds that inhibit the AChE, such as anabisine (Lisko et al., 2013). Indeed, it had been reported that the anabisine, an alkaloid, and a principal compound of $N$. glauca, reversibly inhibits AChE by binding a serine in the active site of acetylcholinesterase, inhibiting the enzyme completely (Dobren'kov et al., 1987; Karadsheh et al., 1991).

We can finally deduce that the important contents in phenolics, and the good biological profiles of $C$. arvensis, C. murale and $N$. glauca, are probably due to the hostile conditions of the marsh area, where these three plants had grown. Indeed the high level of salinity causes stress in the plants from which, they produce much more quantities of secondary metabolites to survive in this conditions (Chanwitheesuk et al., 2005), especially flavonoids to improve a good anti-oxidative response (Reginato et al., 2014; Rezazadeh et al., 2012).

\section{Conclusion}

Globally, these screening investigations indicate that extracts from different aerial parts with different solvent polarities (cyclohexane, dichloromethane, ethyl acetate, acetone and acetonitrile) of the three species $C$. arvensis, C. murale and N. glauca, exhibit different biological activities. Then, confirm the great potential of plants from Chebba marshy region for the production of bioactive compounds, under salinity stress condition, especially polyphenolics and flavonoids.

\section{Conflict of Interest}

The authors declare that they have no conflicts of interest concerning this article.

\section{Acknowledgement}

This research was funded by the Tunisian Ministry of Higher Education and Scientific Research.

\section{References}

Abdel Rahman SM, Abd-Ellatif SA, Deraz SF, Khalil AA. Antibacterial activity of some wild medicinal plants collected from Western Mediterranean coast, Egypt: Natural alternatives for infectious disease treatment. Afr J Biotechnol. 2011; 10: 10733-43.

Abudunia A-M, Ansar M, Taoufik J, Ramli Y, Essassi EM, Ibrahimi A, Khedid K. Evaluation of antibacterial activity of extracts from Calendula aventis flowers. J Chem Pharma Res. 2014; 6: 156-61.

Ahmad B, Jan Q, Bashir S, Nisar M, Shaheen F, Ahmad M. Pharmacological and biological investigations of Chenopodium murale Linn. Asian J Plant Sc. 2003; 2: 1107-11.

Ahmed F, Ghalib RM, Sasikala P, Mueen Ahmed KK. Cholinesterase inhibitors from botanicals. Phcog Rev. 2013; 7: 12130.

Ameyaw Y, Duker-Eshun G. The alkaloid contents of the ethno -plant organs of three antimalarial medicinal plant species in the Eastern region of Ghana. Int J Chem Sci. 2009; 7: 48-58.

Andersen OM, Markham KR. Flavonoids chemistry, biochemistry and applications. CRC Press, Tylor and Francis, 2006, pp 145-54.

Awadh Ali NA, Jülich WD, Kusnick C, Lindequist U. Screening of Yemeni medicinal plants for antibacterial and cytotoxic activities. J Ethnopharmacol. 2001; 74: 173-79.

Chanwitheesuk A, Teerawutgulrag A, Rakariyatham N. Screening of anti-oxidant activity and anti-oxidant compounds of some edible plants of Thailand. Food Chem. 2005; 92: 491-97.

Chethan J, Sampath Kumara KK, Shailasree S, Prakash HS. 
Anti-oxidant, antibacterial and DNA protecting activity of selected medicinally important Asteraceae plants. Int J Pharm Pharm Sci. 2012; 4: 257-61.

Ćetković GS, Djilas SM, Canadanovic-Brunet JM, Tumbas VT. Anti-oxidant properties of marigold extracts. Food Res Inter. 2004; 37: 643-50.

Costamagna MS, Ordoñez RM, Zampini IC, Sayago JE, Isla MI. Nutritional and anti-oxidant properties of Geoffroea decorticans, an Argentinean fruit, and derived products (flour, arrope, decoction and hydroalcoholic beverage). Food Res Inter. 2013; 54: 160-68.

Dall'Acqua S. Plant-derived acetylcholinesterase inhibitory alkaloids for the treatment of Alzheimer's disease. Bot Targets Ther. 2013; 3: 19-28.

Dobren'kov AG, Tilyabaev Z, Dalimov DN, Abduvakhabov AA. Anabasine and cytisine derivatives as reversible cholinesterase inhibitors. Chem Nat Compd. 1987; 1: 97-100.

Ellman GL, Courtney KD, Andres Vjr, Featherstone RM. A new and rapid colorimetric determination of acetylcholinesterase activity. Biochem Pharmacol. 1961; 7: 88-95.

Emeka EJ, Oluwatoyin AE, Adekunle OI, Ignis IO. Preliminary phytochemical screening and evaluation of hypoglycemic properties of the root extract of Uveria chamae. Bangladesh J Pharmacol. 2015; 10: 326-31

Ercetin T, Sezer Senolb F, Erdogan Orhanb I, Tokerb G. Comparative assessment of anti-oxidant and cholinesterase inhibitory properties of the marigold extracts from Calendula arvensis L. and Calendula officinalis L. Ind Crop Prod. 2012; 36: 203-08.

Güven K, Yücel E, Çetintaş F. Antimicrobial activities of fruits of Crataegus and Pyrus species. Pharm Biol. 2006; 44: 79-83.

Jallali I, Megdiche W, M'Hamdi B, Oueslati S, Smaoui A, Abdelly C. Changes in phenolic composition and antioxidant activities of the edible halophyte Crithmum maritimum L. with physiological stage and extraction method. Acta Physiol Plant. 2012; 34: 1451-59.

Kaileh M, Berghe WV, Boone E, Essawi T, Haegeman G. Screening of indigenous Palestinian medicinal plants for potential anti-inflammatory and cytotoxic activity. J Ethnopharmacol. 2007; 113: 510-6.

Karadsheh N, Kussie P, Linthicum DS. Inhibition of acetylcholinesterase by caffeine, anabasine, methyl pyrrolidine and their derivatives. Toxicol Lett. 1991; 55: 33542.

Kchaou M, Ben Salah H, Mhiri R, Allouche N. Anti-oxidant and anti-acetylcholinesterase activities of Zygophyllum album. Bangladesh J Pharmacol. 2016; 11: 54-62.

Kirby AJ, Schmidt, RJ. The anti-oxidant activity of Chinese herbs for eczema and of placebo herbs. J Ethnopharmacol. 1997; 56: 103-08.

Kintzios SE, Barberaki MG. Plants that fight cancer. CRC Press, Beth Budny, USA, 2004, pp 195-241.

Lisko JG, Stanfill SB, Duncan BW, Watson CH. Application of GC-MS/MS for the analysis of tobacco alkaloids in cigarette filler and various tobacco species. Anal Chem. 2013; 85: 338084 .
Liu YR, Li WG, Chen LF, Xiao BK, Yang JY, Yang L, Zhang CG, Huang RQ, Dong JX. ABTS•+ scavenging potency of selected flavonols from Hypericum perforatum L. by HPLCESI/MS QQQ: Reaction observation, adduct characterization and scavenging activity determination. Food Res Inter. 2014; 58: 47-58.

Mabrouk L, Ben Brahim M, Hamza A, Bradai MN. Diversity and temporal fluctuations of epiphytes and sessile invertebrates on the rhizomes Posidonia oceanic in a seagrass meadow off Tunisia. Mar Ecol. 2014; 35: 212-20.

Maisarah AM, Asmah R, Fauziah O. Proximate analysis, antioxidant and anti-proliferative activities of different parts of Carica papaya. J Tissue Sci Eng. 2014; 5: 1-7.

Maisuthisakul P, Suttajit M, Pongsawatmanit R. Assessment of phenolic content and free radical-scavenging capacity of some Thai indigenous plants. Food Chem. 2007; 100: 1409-18.

Marinova EM, Yanishlieva NV. Anti-oxidative activity of extracts from selected species of the family Lamiaceae in sunflower oil. Food Chem. 1997; 58: 245-48.

Montiel-Ruiza M, González-Trujanob ME., Déciga-Campos M. Synergistic interactions between the anti-nociceptive effect of Rhodiolarosea extract and B vitamins in the mouse formalin test Rosa. Phytomedicine 2013 ; 20: 1280-87.

Mukherjeea PK, Kumarb V, Malb M, Houghton PJ. Acetylcholinesterase inhibitors from plants. Phytomedicine 2007; 14: 289-300.

Murraya AP, Faraonia MB, Castroa MJ, Alzaa NP, Cavallaro V. Natural AChE inhibitors from plants and their contribution to Alzheimer's dsease therapy . Curr Neuropharmacol. 2013; 11: 388-413.

Ng YP, Tsun Or TCh, Ip NY. Plant alkaloids as drug leads for Alzheimer's disease. Neurochem Inter. 2015; 89: 260-70.

ÖzçelikB, KartalM, OrhanI. Cytotoxicity, antiviral and antimicrobial activities of alkaloids, flavonoids, and phenolic acids. Pharm Biol. 2011; 49: 396-402.

Pratt DE. Natural anti-oxidants of soybean and other oil-seeds. In: Simic, M.G., Karel, M. (Eds.), Aut-oxidation in food and biological systems. Plenum Press, New York, 1980, pp 28392.

Quettier-Deleu C, Gressier B, Vasseur J, Dine T, Brunet C, Luyckx M, Cazin M, Cazin JC, Bailleul F, Trotin F. Phenolic compounds and anti-oxidant activities of buckwheat (Fagopyrum esculentum Moench) hulls and flour. J Ethnopharmacol. 2000; 72: 35-42.

Raina H, Soni G, Jauhari N, Sharma N, Bharadvaja N. Phytochemical importance of medicinal plants as potential sources of anticancer agents. Turk J Bot. 2014; 38: 1027-35.

Rauha JP, Remes S, Heinonen M, Hopia A, Kähkönen M, Kujala T, Pihlaja K, Vuorela H, Vuorela P. Antimicrobial effects of finnish plant extracts containing flavonoids and other phenolic compounds. Int. J Food Microbiol. 2000; 56: 312.

Re P, Proteggente R, Pannala N, Yang A, Rice-Evans CMA. Anti-oxidant activity applying an improved ABTS radical cation decolorization assay. Free Radical Biol Med. 1999; 26: 1231-37. 
Reginato MA, Castagna A, Furlàn A, Castro S, Ranieri A, Luna V.Physiological responses of a halophytic shrub to salt stressby $\mathrm{Na} 2 \mathrm{SO} 4$ and $\mathrm{NaCl}$ : Oxidative damage and the role of polyphenols in anti-oxidant protection. AoB Plants. 2014; 6.

Rezazadeh A, Ghasemnezhad A, Barani M, Telmadarrehei T. Effect of salinity on phenolic composition and anti-oxidant activity of artichoke (Cynara scolymus L.) leaves. Res J Med Plant. 2012; 6: 245-52.

Saidi S, Bouri S, Ben Dhia H, Anselme B. A GIS-based susceptibility indexing method for irrigation and drinking water management planning: Application to Chebba Mellouleche Aquifer, Tunisia. Agric. Water Manage. 2009; 96: 1683-90.

Selmar D, Kleinwächter M. Stress enhances the synthesis of secondary plant products: The impact of stress-related overreduction on the accumulation of natural products. Plant cell Physiol. 2013; 54: 817-26.

Sohn HY, Son KH, Know CS, Kan SS. Antimicrobial and cytotoxic activity of 18 prenylated flavonoids isolated from medicinal plants: Morus alba L., Morus mongolica Schneider, Broussnetia papyrifera (L.) Vent, Sophora flavescens Ait and Echinosophora koreensis Nakai. Phytomedicine 2004; 11: 666-72.

Tabana YM, Dahham SS, Ahmed Hassan LE. In vitro antimetastatic and anti-oxidant activity of Nicotiana glauca fraction against breast cancer cells. Adv Biol Res. 2015; 9: 95-102.

Tsuchiya H, Sato M, Miyazaki T, Fujiwara S, Tanigaki S, Ohyama M, Tanaka T, linuma, M. Comparative study on the antibacterial activity of phytochemical flavanones against methicillin-resistant Staphylococcus aureus. J Ethnopharmacol. 1996; 50: 27-34.

Waterman PG, Mole, S. Analysis of phenolic plant metabolites. Blackwell Scientific Publications, Oxford, UK, 1994, pp 85-87.

Zain ME, Awaad AS, Al-Outhman MR, El-Meligy RM. Antimicrobial activities of Saudi Arabian desert plants. Phytopharmacology 2012; 2: 106-13. 


\section{Your feedback about this paper}

1. Number of times you have read this paper 0

2. Number of times you have seen the video clip 0

3. Quality of paper

$\bigcirc$ Excellent $\bigcirc$ Good $\bigcirc$ Moderate $\bigcirc$ Not good

4. Your comments

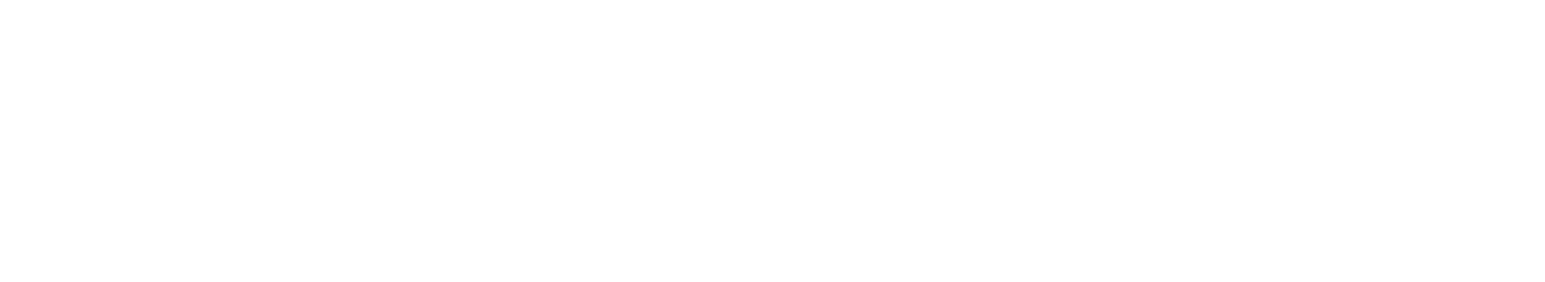

